\title{
Two Suns? Data, Algorithms, Spaces and Techno Feudalism
}

\begin{abstract}
Algorithms are opinions embedded in code. It's really different from what you think most people think of algorithms. They think algorithms are objective and true and scientific. That's a marketing trick. It's also a marketing trick to intimidate you with algorithms, to make you trust and fear algorithms because you trust and fear mathematics. A lot can go wrong when we put blind faith in big data.

- Cathy O’Neill Ted Talk 2017
\end{abstract}

A main thread in the Two Suns? series might be summed up as follows. There are several spaces or forms of space involved; territorial space, outer space, cyberspace and living space, And there is data to be found and owned in each of these spaces. That data may be processed using algorithms in each space and across all spaces. 
With such a thread in mind one argument in the Two Suns? series so far and going forward is as follows; we should treat Big Tech as an incipient state with its own entry and exit points and its own infrastructure rather than constantly framing discussion in terms of a nation-state like the USA. The latter may have been and may still be a host for the Algorithmic State but this is not necessarily ongoing. Furthermore there is a range of nation states from the strong to the barely formed ranging through, say the examples of the USA, Australia and Myanmar and a varying use and influence of the algorithm within these nation states.

There is also a range of strategies and situations in the Big Tech sphere across spaces with, for example, Netflix having an extensive and well formulated international strategy while others do not. Another difference perhaps critical eventually might be that one or two Big Tech players like Amazon along with Spacex operate satellites in near space in shells that surround rather than being defined by nation states while Facebook, for example, remains in cyberspace.

Most academic commentary regarding Big Tech has the nation-state as the first port of call. In reviews of literature in this series, by far the greater part of the literature found is about regulation of Big Tech by nation-states singly or collectively or has the nationstate at the centre of enquiry. Apart from asking what kind of nation state we are talking about- it is 
usually the USA or a European entity- one might also ask about variations in power amongst and between nation states as well as varying kinds of power in associations of nation-states.

At what point does the host become a carcass? In such a case energy might shift from an earlier entity to an emerging one. In an extreme case like Myanmar we have had the example in early 2021 of Facebook, a major media player there, actually locking out government commentary, said government in this case being that of the military but nonetheless we have an algorithmic actor draining or closing out the energy of a political actor. In the case of Australia $\mathrm{v}$ Facebook, also in early 2021, we have a standoff regarding advertising dues and a mixed response where Australia seems to have won a limited arrangement to suit but not without a fight and not without concessions some of which are difficult to plumb as they seem, at first glance anyway, to favour media conglomerates.

Similar questions are being asked in smaller countries like New Zealand. In a New Zealand Herald Premium article of 21.03.20 Damien Venuto asks whether the appropriate Minister, Kris Faafoi, should take a harder line on taxing Google and Facebook. Venuto welcomes the news that Google and Facebook are engaging in 'media funding intiatives' in Australia as well as New Zealand but sounds a note of caution: 
...this agreement exists outside the realm of any real regulation. It's essentially a unilateral decision by a tech giant to distribute money back to New Zealand.

This agreement also does nothing to address the long-running issues of major tech companies avoiding full taxes by offshoring their handsome revenue figures in countries such as Ireland and Singapore.

Nor does it address the plight of smaller media companies that won't have the scale to generate enough revenue from anything Google is offering.

Venuto's article well states the gap between countries with a certain scale such as Australia and those like New Zealand which are really outside the wall as far as Big Tech is concerned. Continuing with sharp but clear language Venuto sums up the situation of a small country like New Zealand as follows:

...the Government has also asked the Ministry of Arts, Culture and Heritage to look into what regulatory steps could be taken to address the financial pressures on local media companies.

There has, however, been no indication from the Government that New Zealand should expect legislation akin to what has been seen in Australia...In the global financial context, New Zealand whining would be about as alarming to the tech giants as a fly buzzing around a cow's tail. 
In an important aside Venuto notes the alliance of state and media companies involved. It is also interesting to think, as he might seem to, about Big Tech and Big Media as New Media and Old Media:

...Australia always had more bargaining power. Our neighbours across the ditch also had the added clout of billionaire media magnate Rupert Murdoch, who pushed hard for a deal favourable to his media properties...Australia essentially became the chosen venue for a slugfest between the lords of old and new media.

Given the power of Big Tech, whatever happens small countries like New Zealand might be advised to be astute and discreet simply because, as Venuto notes above these smaller countries have little power in the global financial context. In another note regarding associations of countries, possibly also important as a way forward for the smaller countries, Venuto writes:

Faafoi will also be aware that the OECD talks involving more than 100 countries on a major rewrite of global tax rules are coming down to the wire. Collaborating with this much larger group could result in the necessary change without the need for a public spat between New Zealand and any number of the world's tech giants. 
Combinations of nation states with combinations of algorithmic states come in all shapes and sizes. At the beginning of the Two Suns? series I went a long way back to my writing on the early state, referring to an article of 1983 about Maori society in the nineteenth century. In that case there was a state emerging in an emerging state, one incipient state, as it were, in the context of another, the former being a large grouping of iwi, tribes in the central North Island gaining momentum I suggested from around 1750 and developing into the entities like the King Movement, the latter being the settler state developing in New Zealand from 1840 and then strengthening in the late eighteen fifties.

In the present case how do things work when one form of state, the Algorithmic, competes with another, the Nation state? To take events from early 2021 we have regulation by the Algorithmic of the Nation state. One thinks of Twitter shutting down Donald Trump, then the President of the United States of America- albeit in the last days of his presidency or, as mentioned above, of the lockout of the military government by Facebook in Myanmar. It may be worth pointing to the fact that the well developed nations are few. There is the USA, Britain, the Europeans and, way over there, is China, Then there are the rest of the countries in the world. Some of these like, say Australia or South Africa or India have the scale and strength to stand up to Big Tech but there are many countries in the situation of New 
Zealand as described above by Venuto that simply do not have the scale of resources to resist Big Tech and then there are a set of countries like Myanmar or Zimbabwe that teeter on collapse as political and economic entities. To say that the majority of nation states in the world are vulnerable to Big Tech is not a stretch.

To take another example from the New Zealand experience with big tech involving Memorandums of Understanding with Amazon, Radio New Zealand reported on 16.04.21:

A deal to boost the local economy has been struck between the government and the global giant Amazon.

The company is currently filming a Lord of the Rings TV series in New Zealand.

Under a Memorandum of Understanding Amazon will get an extra 5 percent from the Screen Production Grant in addition to the 20 percent grant the production already qualifies for.

Amazon plans to spend about $\$ 650$ million on season one of the show meaning it would be eligible for a rebate of over $\$ 160 \mathrm{~m}$.

A striking feature is just how positive and uncritical has been the Government response in a small country like New Zealand to an overture from Amazon: 
Minister for Economic Development and Tourism Stuart Nash told Morning Report the deal secured multi-year benefits to New Zealand and the subsidy was well worth it.

"This is fantastic, it really is," Nash said.

...Nash said the amount Amazon would receive is not more than what any other international company would be eligible for if they met the tests. "I think what we have got out of Amazon in terms of the MOU and the industry and how we're going to train people and our ability to use footage for tourism, the ability to leverage off a lot of what Amazon is doing, is fantastic."

"The bottom line is if we want a film industry in this country, part and parcel of that is government subsidies.

"Where's the downside?"

As the discussion below of techno feudalism proceeds the downsides might become apparent. This is an example of a soft power approach through the arts- the arts meaning money in a country deprived of the tourist dollar in a pandemic- with other matters like the possibility of an Amazon distribution centre only being a rumour at this stage as Minister Nash notes in the Radio New Zealand report.

It is also an example of Amazon working out arrangements in a small country through a complex of Memorandums of Understanding with Ministries and Government agencies. Instead of a whole of 
government approach Departments and Ministries are the parties to the contract with Amazon.The report goes on:

Two Memoranda of Understanding (MOU) were signed in December 2020 following negotiations between Amazon and the New Zealand Film Commission, Tourism New Zealand and the Ministry of Business, Innovation and Employment. An overarching MOU was signed to establish the key principles and obligations under the 5 percent uplift, and a season one-specific MOU is also in place.

Subsequent season MOUs would be negotiated for each future season.

The MOU has three parts, with Tourism New Zealand taking the lead on branding.

There is also the alignment of Big Tech and nation state interests:

"This provides the opportunity for New Zealand to strengthen its international brand, with a campaign to promote New Zealand as the 'Home of the Lord of the Rings' series, timed to coincide with the airing of the first season on international screens...

"Amazon and MBIE will work together to establish agreed-upon themes that align Amazon's and New Zealand's goals on a season by-season basis. Potential themes include, but are not limited to, technology and innovations that will be used in the production of the series. 
"These themes may explore the specific $R \& D$ focus areas, and the parties agree to work together to explore additional or alternative opportunities as they may arise."

The report concludes on a somewhat disconnected note,

Nash said the deal with Amazon was not linked to rumours of a retail distribution centre being set up locally and this was a different part of the business. "People can go online and buy something from Amazon... I don't think them having a distribution centre here would make any difference to whether people went online or not'.

It should be noted that there are questions about this deal coming from industry groups as this article is going to press.

As well as relations between Big Tech and nation states there are arrangements between tech operators. There is the lockout of one tech operator by another with Amazon shutting down Parler through Amazon Web Services in 2020. Here is an important example of negative interaction between tech operators, a contrast to the co-operation seen in the 'shadowing' of Netflix's Reed Hastings by Facebook's Cheryl Sandberg described later in this article. This kind of negative action, it seems at least from study by the present writer, is unusual.

Looking ahead to the discussion of neo or techno feudalism below, associations, Lodges and various sets and cliques of nobles mattered in their 
collective strength in feudal times and the same might apply in techno feudalism in some kind of Silicon Valley Inc. The 'shadowing' example above may be important as a harbinger of support groupings within the group of Big Tech operators although it ought to be said that there is little in the way of formal associations known to the public.

Part of the problem of concentrating on the developed nation state as a first reference and thinking that the incipient state is somehow en route toward or in the process of becoming a developed nation-state like the USA or the United Kingdom or France is that this course, this trajectory, is, perhaps, flawed. Why should one entity be en route or in the process of becoming another? What I have called the Algorithmic State might be in the process of becoming something very different or becoming more of itself.

To take leadership for example, we are talking, as Giridharadas (2019) suggests, when considering Bezos or Zuckerberg of Amazon and Facebook respectively, of new styles of leadership. This might be called digital leadership. It is not voted in. Does it emerge from the sort of culture described in No Rules Rules a book by Hastings and Meyer on Netflix replete as this book is with phrases like 'instrumental control' and 'internal context'? Or is this 'culture', as also found in such phrases as 'the two pizza rule' in what Dumaine describes as Bezonomics, simply a mask for control of data? 
Speaking of culture- in inverted commas or no- one interesting thing about No Rules Rules is the last chapter where the international context of Big Tech, Netflix in this case, is considered. Hastings and Meyer offer an excellent insight into how a Big Tech operator must work out its own culture and then situate it in the context of that found in nation states. In the case of Japan for example forthright criticism of one's peers will not work as well as in the Netherlands. And so on. This is interesting as Netflix seems to position itself or is positioned by such leaders as Hastings across nation-states at least as much as within a nation state like the United States. The examples of Amazon in New Zealand and Facebook in Australia or in Myanmar may be important here as well.

Coming all the way from China we might be seeing something similar with the listing of Alibaba in America as well as in China. Also interesting is the thought of globalisation in all of this. Formerly the big global energy companies like Exxon would come to mind. Big Tech has, in the main been situated or at least based stateside so to speak, many of them in California, which is discussed in terms of feudalism below.

Outfits like Alibaba and other Chinese Tech companies would seem to be trying to get into the USA via stock exchange listing and that type of thing. There might be a complex of reasons here. Alibaba and the like may be trying to escape China 
and the latest example in April 2021 shows how the Chinese government operates through fines and the like to keep a semblance of control over Jack Ma and his companies. Equally though, Alibaba, Ten Cent, JD and others may simply be growing where their algorithms find space for development, America just being another possibility. Discussed later is the placement of Baidu by its owners in the Cayman Islands.

Considering leadership and the kind of culture involved are we looking at a form of feudalism? This goes by several names in the literature, recent and sparse as that might be as with Neo-Feudalism, Big Tech Feudalism, Techno Feudalism and so on. We may need to consider the matters shared by this or that tech giant as well as the differences, the strategic alliances and the distances between Big Tech operators. Coming back to the point about Neflix above is this an increasing global feudalism or is it located in specific nation states?

In venturing down this path of discussion we might go back to basics and ask what exactly was and is feudalism and also think about the anthropology, the political anthropology of feudalism. This could take us back in cross reference to points earlier discussed like the Maori state or the anthropology of Marshall Sahlins in the Pacific Islands with his discussion of physical contours and associated kinship systems and culture. As this series continues several spaces within which Big Tech 
operates are identified including close outer space where we find the shells of Amazon and Spacex, cyberspace, hubs and the space of the neighbourhood.

Does this set of contours/shapes/different contexts (shells, hubs, cyberspace etc) generate or allow forms of leadership, kinship or citizenship? If so what might these be and, also, what might the preconditions for such be? Furthermore, do they really conform to an idea of feudalism or is this another form of organisation?

Regarding feudalism, one of the surprising, at least at first, aspects of this discussion is to come across an argument that finds feudalism at the heart of America in what is sometimes seen as the most progressive of states, California. While it may or may not be the heart, California is not the same as other places in the USA. California has Silicon Valley and other things that set it apart and, of course, each state is different. But it is a model to begin with and perhaps, even given the presence of Silicon Valley, the best place to start an analysis.

It may be profitable, before considering the example of California, to consider the meaning of feudalism. In 2018, in a paper entitled 'Feudalism - A Political System of Medieval Europe and Elsewhere' K. Kris Hirst suggests that generally 'the term refers to a sharply hierarchical relationship between different levels of landowning classes.' 
Hirst goes on:

Key Takeaways: Feudalism

Feudalism is a form of political organization with three distinct social classes: king, nobles, and peasants.

In a feudal society, status is based on land ownership.

In Europe, the practice of feudalism ended after the Black Plague decimated the population.

A feudal society has three distinct social classes: a king, a noble class (which could include nobles, priests, and princes) and a peasant class. Historically, the king owned all the available land, and he portioned out that land to his nobles for their use. The nobles, in turn, rented out their land to peasants. The peasants paid the nobles in produce and military service; the nobles, in turn, paid the king. Everyone was, at least nominally, in thrall to the king, and the peasants' labor paid for everything.

Along the way and before concluding that feudalism ended with the Black Death of 1347-51 (this might be a contrast to the current Coronavirus pandemic in that, if anything, the grip of Big Tech on populations seems to have increased as the pandemic has developed) Hirst also gives the following characteristics of feudalism:

Throughout history and today, feudalism arises in places where there is an absence of organized 
government and the presence of violence. Under those circumstances, a contractual relationship is formed between ruler and ruled:

the ruler provides access to the required land, and the rest of the people provide support to the ruler. The entire system allows the creation of a military force that protects everyone from violence within and without.

In an important point that we might return to Hirst points out:

In England, feudalism was formalized into a legal system, written into the laws of the country and codifying a tripartite relationship between political allegiance, military service, and property ownership.

Hirst suggests, as quoted below, that feudalism began in England through the law, the alteration of the common law after the Norman Conquest in 1066 and it may be that we would do well to look at Big Tech and the law. This may be seen in the Milan school and their idea of the Algorithmic State in which the law of nation states is fundamental. Also, the Yale scholar Lina Khan is important in such a consideration as pointed out earlier and discussed later regarding Lina Khan's interview by Stephen Sackur on the BBC. Khan's fear that the weakness of anti trust legislation or at least the strictures on that legislation via the Chicago School 
allows power of a new kind to occur may relate to this idea of preconditions for feudalism occurring in law.

Such an argument rests on the weakness of the law in the case of techno feudalism whereas, in the Hirst argument at least, there were matters in the law following the alteration of the common law after the Norman Conquest that supported the growth of feudalism. To return to Hirst:

English feudalism is thought to have arisen in the 11 th century $\mathrm{CE}$ under William the Conquerer, when he had the common law altered after the Norman Conquest in 1066. William took possession of all of England and then parcelled it out among his leading supporters as tenancies (fiefs) to be held in return for services to the king.

Those supporters granted access to their land to their own tenants who paid for that access by a percentage of the crops they produced and by their own military service. The king and nobles provided aid, relief, wardship and marriage and inheritance rights for the peasant classes.

In these arguments every precondition seems to fall back on another. Hirst, for example, points to the preconditions for such a legal context:

That situation could arise because Normanized common law had already established a secular and 
ecclesiastical aristocracy, an aristocracy that relied heavily on the royal prerogative to function.

Below there is an interesting use of the term 'clerisy' in Kotkin's discussion of California as he talks about a supporting cast for Big Tech and this would seem to be like the 'secular and ecclesiastical aristocracy' that Hirst mentions above. Hirst does note that feudalism is a worldwide phenomenon and refers to the United States:

American founding father Thomas Jefferson was convinced that the new United States was practicing a form of feudalism in the 18th century. He argued that indentured servants and enslavement were both forms of yeoman farming, in that access to land was provided by the aristocracy and paid for by the tenant in a variety of ways.

Hirst discusses the near universality of feudalism in certain parts of the world such as Europe and the course of feudalism there:

Just before the rise of the black plague in the 14th century, feudalism was firmly established and working across Europe.

This was a near-universality of family-farm tenure by conditionally hereditary leases under noble, ecclesiastical or princely lordships who collected cash and in-kind payments from their subject villages. 
The king essentially delegated the collection of his needs-military, political and economic-to the nobles.

By that time, the king's justice-or rather, his ability to administer that justice-was largely theoretical.

The lords dispensed the law with little or no kingly oversight, and as a class supported each other's hegemony.

Peasants lived and died under the control of the noble classes.

Interestingly, Hirst does not talk much about the transmission of culture and ideology that went on or goes on in feudalism. The things seen and heard at the village fete or at jousting and other ways of sharing experience and attitudes, for example. These venues and contexts were owned by the nobles or suffused with their power. Later the cultural and aesthetic power of Big Tech and the ownership of studios by the likes of Prime and Netflix is considered.

Just as control of entertainment is important, going back to Orwell so is the control of truth. One aspect of techno feudalism that sets it apart from earlier forms is the power to lie. Not only does Big Tech own the data it also controls the algorithms that, as we shall see, after Sauter and O'Neill and others as this series develops, can spin the data. The person on the street without data of scale and without the use of significant algorithms cannot do this and because 
Big Tech owns data and controls algorithms on a scale that many governments do not then Big Tech becomes, after Orwell, the Ministries of Truth.

As mentioned in the next section, Six the development of Wikipedia offsets some of the spin from Big Tech.

With Orwell and other writers in mind we might go back to commentary on propaganda at this point. What might Big Tech be propagandising? There is a discussion in the next section of this Two Suns? series, Six, of the Cambridge Analytica example which speaks to this.

The advocates of the techno feudal argument would equate Big Tech with the noble classes and with the above definitions and qualifications of feudalism in mind we might turn to the work of Anand Giridharadas (ibid) and others including an excellent article in American Affairs by Joel Kotkin entitled 'Neo-Feudalism in California'.

Kotkin begins with a quote from Kevin Starr:

From the beginning, California promised much. While yet barely a name on the map, it entered American awareness as a symbol of renewal. It was a final frontier: of geography and of expectation.

Kevin Starr, Americans and the California Dream: 1850-1915 
Kotkin goes on to mention and cite from a Post on Medium by Peter Leyden and Ruy Teixeira entitled California is the future of American politics. Referring to that title Kotkin then punches in:

If true, this may not be the best of news. Rather than the vanguard of a more egalitarian future, California has become the progenitor of a new form of feudalism characterized by gross inequality and increasingly rigid class lines...But the shift is likely to only further enhance those at the top of the state's new class structure, those best suited for the inexorable and expanding shift to digital platforms. These are the tech oligarchs who dominate an economy that leaves most Californians less well off.

In an interesting twist when thinking about the Black Plague as the end of feudalism Kotkin suggests that the Coronavirus pandemic and the consequent shift to remote work is helping the growth of techno feudalism:

The shift to online services is likely to boost the already established large tech firms, particularly those involved in streaming entertainment services, food delivery services, telemedicine, biomedicine, cloud computing, and online education. The shift to remote work has created an enormous market for applications, which facilitate video conferencing and digital collaboration... As we stare at our screens, we are evermore subject to manipulation 
by a handful of "platforms" that increasingly control the means of communication.

In an important note about inequity Kotkin points out the development of Big Tech from 'garage culture'. This relates to the homespun idea of tech leaders in startup mode as with Bezos in a garage with one partner, Zuckerberg and one or two others operating out of a student dormitory or whatever and the general spinning of a digital leadership myth after Horatio Alger. This myth is discussed further in this Two Suns? series and is well treated by Anand Giridharadas (ibid). Kotkin argues:

All this is likely to accelerate the state's trend towards extreme inequality. Although successors of the state's entrepreneurial "garage culture," these firms clearly are not raising all boats and creating opportunities for a broad portion of the population.

Kotkin concludes his introductory remarks with a reference to the economist, James Galbraith suggesting that California is becoming more unequal and saying that California now suffers a level of inequality worse than that of Mexico. He goes on to talk about the evolution of California's economy from a diverse set of opportunities to something else again: 
As recently as the period from 1996 to 2006, according to economist David Friedman, California's job creation was well distributed among regions, job types, and incomes. But in the recovery after the Great Recession, which hit California more profoundly than the rest of the country, the state's economy has become more narrowly focused and geographically constrained around the tech-driven Bay Area.

Kotkin gives a wide set of results to back up his point and arrives at the result that "These economic changes have pummeled the middle class-traditionally the bulwark against feudalization." The next section of Kotkin's paper is entitled Silicon Valley: A Feudal Castle Town and he goes on to say:

...as Silicon Valley has shifted from an industrial to a software focus, it lost over 160,000 manufacturing positions. Even worse, as much as 40 percent of the current tech workforce is made up of noncitizens, many on temporary visas.

In the process, Silicon Valley has morphed into what CityLab has described as "a region of segregated innovation," where the rich wax, the middle class declines, and the poor live in increasingly inescapable poverty...

Rather than being a beacon of opportunity, the City by the Bay is a place where the middle-class family heads towards extinction. San Francisco also suffers the highest property crime and petty crime rates of any major urban area, and it has become 
the epicenter of an explosion in homelessness, even as homelessness has been reduced in much of the country.

Using an array of statistics to back up his argument Kotkin continues:

For the next generation of Californians, arguably the best way to buy a home is a distinctly feudal one: win the birth sweepstakes and tap the Bank of Mom and Dad to make a purchase.

With fewer young people now Kotkin suggests that rather than the surfboard, the wheelchair will be the state icon of California. Citing the economist Husing's work on the Inland Empire and others Kotkin offers something of a map"

The most extreme poverty is found in two places: the vast interior regions and areas close to urban cores. Anyone riding along Highway 33 through the Central Valley can see scenes that seem more like rural Mexico than America: abandoned cars, dilapidated houses, and deserted storefronts.

Throughout this series an effort has been made to scope the minority situation especially where there is a state within a state situation. As a critical thought we might look again at the 'no knock on effect' where there is no trickle down or cross over of benefits from one community to the other. In New 
Zealand there are two communities side by side in the Bay of Islands, one that might be described as tech savvy in Kerikeri while adjacent is an extremely poor community without tech in the form of computers, without resources generally and without running water in places.

Kotkin offers an excellent analysis headed The Failing Race Card, saying:

Hispanics and African Americans do worse in California than almost anywhere else in the country.

What is the POV from Big Tech? Kotkin put the oligarchic mentality as follows,

California's tech oligarchs may be famously woke, but they do not seem to be greatly concerned by the enormous gaps in class and race in their backyards. ...Better to be a child in an African village, a whale, or a tree than someone forced to live in their car across the street from Google.

This reflects the oligarchs' remarkable level of narcissism, elitism, and self-regard...They justify their position by embracing the notion that they are not just creating value but working to "change the world." This makes them-unlike the merely profitoriented old managerial aristocracy or the grubby corporate speculator-intrinsically more deserving of their wealth and power.

These tech oligarchs do not oppose huge class divisions; rather, they embrace what Aldous Huxley called "a scientific caste system," in which they stand at the apex. In some ways, this reflects the 
realities of the current tech business, which relies not on a wide range of skills but on a small cadre of elite "talent."

Referring back to the book No Rules Rules about Netflix the last point above certainly has resonance as Hastings and Meyer champion the selection and maintenance of such an elite 'talent'.

Kotkin then talks about the way forward in a section called The Road to Oligarchic Socialism:

Rather than fight inequality, the oligarchs are seeking ways to accommodate it... If anything, they tend to push what might be called an antimaterialist point of view that emphasizes "meaningful community" on a global scale but rarely speaks of upward mobility.

Later in the Two Suns? series the ideas of cobotics and the consumer farm are considered. In a brilliant comment from a resoundingly good paper Kotkin, via Ferenstein, may be talking about something similar:

Ferenstein suggests that many oligarchs, in contrast to business leaders of the past, seek to secure their future by creating a radically expanded welfare state. Indeed, the former head of Uber, Travis Kalanick, Y Combinator founder Sam Altman, Mark Zuckerberg, and Elon Musk all favor 
a publicly funded guaranteed annual wage-in part to help allay fears of potential insurrection arising from the effects of "disruption" on an exposed workforce. In a sense, the oligarchs have embraced the old aristocratic notion of what Marx called a "proletarian alms bag" by having taxpayers provide not just guaranteed wages but free health care, free college, and housing subsidies.

This oligarchic socialism differs dramatically from the mixed capitalist system that emerged after the Second World War, which was based on increased upward mobility and increased consumption for the masses. In the world envisioned by the oligarchs, the poor would become ever more dependent on the state, as their labor is devalued by regulatory assaults on the industrial economy, as well as by the greater implementation of automation and artificial intelligence. Even those lucky enough to work for the oligarchs will face a severely restricted future. Unable to grow into property-owning adults, these workers will subsist on subsidies and what they can make through gig work; to combat boredom, they can enjoy what Google calls "immersive computing" in their spare time.

Who helps the tech oligarchs, who enables them? Kotkin addresses this in a section entitled, The Alliance with the Clerisy. The last word, 'clerisy' is important perhaps as there is an echo of the court, the consensus of the feudal court, a murmur of collective power in the elite. Kotkin is suggesting a form of patronage: 
To cement their dominion, the oligarchs have made political alliances with other groups, notably those who dominate California's increasingly one-party system. This has made them critical allies of California's progressives, with whom they have made common cause on a host of issues, from gender rights to immigration to climate change.

This alliance between the oligarchs and California's clerisy-university professors, senior bureaucrats, and nonprofits-drives the state's powerful green agenda...the clerisy, cloistered in powerful institutions like academia, the media, or government, are largely insulated from the ill effects of the regulatory regime, which include higher energy and housing prices.

Moving across the world we can see that the Californian example has resonance. Ramon Bleuca 2020 talks about 'digital feudalism in a multipolar, unstable world' in an article in Responsible Statecraft. Bleuca begins by setting out the context of Covid 19 in the world and then in a few succinct sentences makes the following case:

The influence of powerful non-state actors in the international stage was already becoming more relevant than the classic power struggles among states at the height of globalization. States have been progressively losing their exclusive role in the construction of the multilateral international system. 
Now, their diminished sovereignty has to do with the increased power and influence of transnational corporations - of which Big Tech is the ultimate example - the privatization of military force, and the international role of private armies and militias, transnational terrorist organizations, and drug cartels and other criminal groups.

The institutional and economic architecture put in place at the end of World War II - which has made possible one of the longest periods of stability and prosperity in recent history - is currently in turmoil and not so much because of the so-called revisionist states.

One feature in most if not all descriptions of feudalism is the presence of a military force. Interestingly, this is not so far part of the repertoire for Big Tech. Not one of the operators seems to have a private militia. Is this why the USA is such a good host state for Big Tech, because of the formidable protection for citizens, corporate or other that the armed forces there provide?

Bleuca looks at populist leaders and concludes that there is no way back. His article was published in the last year of Trump and talks about his influence making some important points for the Post-Trump era:

The illusions of populists and other enemies of liberal multilateralism about their capacity to replace an international order they consider weak 
and ineffective with a return to the safety of state sovereignty and unilateral policies, are as unrealistic as those that still believe the international institutional architecture is solid enough to endure the current geopolitical shocks without decisive action.

In a very powerful way Bleuca describes where we now find ourselves:

This is a scenario closer to the condottieri and mercenary bands of medieval Europe than a return to the golden age of state sovereignty...The shift in the tectonic plates of international politics is pointing towards a highly unstable multipolar system in which post-Weberian states with diminished sovereignty will coexist with an eroded multilateral architecture and powerful non-state actors.

The description above certainly fits with Afganistan or Myanmar and, as Bleuca suggests below, Syria, Lebanon, Iraq, Libya, or Yemen but, as implied by the present writer above, the USA has an armed force that floats above its geographical position in the world and, at least for the time being, may be giving shelter to Big Tech. Bleuca continues:

The trust of citizens in their leaders and liberal democracy has been diminishing rapidly in the past decade, in parallel with the growth of social media. 
The problem is deeper than the effect of fake news or defective governance or corruption.

The narrative of the international liberal order of ever-increasing prosperity fueled by endless economic growth is not credible anymore. The situation in the Middle East offers a particularly stark example of how this crisis can accelerate a process of authority fragmentation, institutional collapse, rampant corruption and failed governance.

Syria, Lebanon, Iraq, Libya, or Yemen already can be considered test cases of this neo-medieval model, in which non-state actors are already the main decision makers...Growing inequalities, the effects of climate change, future scarcity of resources, the impact of unprecedented population displacements, and the return of health hazards we thought were eradicated are a breeding ground for cataclysmic transformation.

Bleuca then talks about data and control:

Artificial Intelligence is developing rapidly and the connection between massive data harvesting and biometric monitoring with the implications of $5 \mathrm{G}$ technology will multiply the capacity of governments to control their citizens. If the rise of surveillance states is a matter of serious concern, it is even more worrying that the new technological instruments and personal data is actually in the hands of powerful private corporations. If not addressed now, the collusion between the 
surveillance state and digital feudalism will blur the difference between totalitarian and democratic states in ways that are still difficult to imagine. Many of the emergency measures taken now will become a fixture of life as the whole historical process will be fast-forwarded. The choice between totalitarian surveillance and citizen empowerment or between nationalistic retrenchment and expansion of globalization will shape the coming historical cycle.

Personal data harvesting is fueling the growth of the technological behemoths, attracting a growing share of all global investment in detriment of the productive economy, job creation, and social infrastructure.

To turn the screw that Bleuca fashions, the aspect of techno feudalism that is shocking when we pause to think about it is that, as Neil Godfrey puts it in the title of his paper of 2021-02-23, 'TechnoFeudalism - We are working for Big Tech for free'. In a discussion imagined by Godfrey one person says "Facebook's users provided both the labour that went into the machine and the product that was sold by it."

Knowing that "Facebook pays only 1 per cent of its revenues to its employees and precisely nothing to its users" it is realised in 2025 that: 
...no self-respecting liberal could condone big tech's mass manipulation techniques nor defend its gains as a fair reward for entrepreneurship. Its returns were only made possible by a species of technofeudalism that made billions of people work for it for free.

Feudalism is a system of power and control, of order and, it is important to realise, of law. It became codified. Now might be a good time to check how Facebook and other Big Tech operators codify and strengthen their positions.

Tempting as it might be to accept feudalism as a guiding light for analysis we might also look further afield for useful forms of analysis. We could go back to Weber and talk about charismatic leaders and theories of charisma when think about Bezos, Musk, Gates and the like. Or are these leaders simply riding a new form of capital which is data ('in data we trust') combined with efficient algorithms. Is the success of Big Tech to do with governments not owning data while the big tech companies do? Is a data bank comparable to a treasury?

Can we relate the idea of kings, nobles and serfs to Big Tech? Certainly the books Bezonomics and No Rules Rules discussed throughtout the Two Suns series would seem to suggest so. Nobles always owned land at the sometimes loose discretion of a King. Is the allocation of shells in space to Amazon and Musk's Spacex comparable? Can we think of 
these as fiefs? This raises questions of the allocation of space and power. If some random committee or board is allocating sections of space which then, by accident as it were, turn out to have significant power then much of this might be seen as inadvertent. On the other hand, this might simply be an intelligent use of their considerable technological resources by Musk and Bezos.

Is there an equation or a similarity between nobles and their courts and say Amazon and Prime entertainment. Did each noble provide some circus as well a little bread to the serfs? Do the serfs come to naturally pivot to that type of entertainment with its stresses and its absences, to their accustomed 'culture'?

Do the nobles run plays where they select the scenes and instruct the playrights? Do the nobles say who to invite and what story to tell? Then there are the studios as well as the court theatres. How to paint as well as who to paint and in what light?

Amazon owns Prime and controls the narrative there. Who to invite and what they might say. How to cut the movie today in the Amazon-Prime world might be like how to paint the portrait in the world of the feudal noble. We could digress into a discussion of Las Meninas and the role of the artist in all this but some things seem to equate. For example the paying by nobles of nominal lip-service to kings in a feudal situation is like Big Tech and the nation state as in the examples of Myanmar and 
Australia cited at other points in the Two Suns? series.

So we have a set of players who tend to find a centrality to what they do. This may be cultural practice. We could note again the influence of Collins and the workaday formulae of the two pizza rule at Amazon or the Netflix Innovation Cycle. The central shared features might be found in entertainment and the analogies of court theatre for nobles and Prime to Amazon might be noted again. Or it might be usage of a state apparatus as Silicon Valley uses California and most Big Tech operators use the USA as a home.

But in all these cases and elsewhere perhaps there is a tendency to find common ground, to 'shadow' one another and savour the 'secret sauce' as Jim Collins puts it, of one another. Then there is the sharing of management knowledge, the other end of the 'culture' which is the nobles running the serfs, Silicon Valley running the rest of California. In their book No Rules Rules, Netflix and the Culture of reinvention, Hastings and Meyer (2020: 130) cite a visit to Netflix from Cheryl Sandberg of Facebook who follows Hastings around at Netflix in a 'shadowing' exercise as she takes notes and keeps quiet. This is like farmers sharing informative walks around the farm with other farmers. It is standard practice as the book implies. It is like Nobles attending jousting or theatrical displays or dinners, all places where the culture of feudalism might be 
shared. Where is the research, and it would be important research on how do Big Tech companies combine and agree on shared plans of action? This series began with a consideration of the Maori King movement. Can we compare the tribal or- at least occasionally- pan tribal situation in AotearoaNew Zealand to feudalism or a feudal system?

There are differences in the Big Tech operators. As noted elsewhere Bezos and Amazon are in close outer space and Zuckerberg and Facebook are not. At the same time, there are shared influences on corporate culture across entities. One thinks again of the influence of Jim Collins, the two pizza rule in Amazon, the no rules rules of netflix and other slogans or rallying points. The main common point among tech feudal systems though is control of data and effective use of algorithms.

One also thinks though of critics like Scott Galloway who would like to break up Big Tech. And one considers ways to oppose the power of the data harvesters. This is explored more fully in Seven with reference to the excellent work of Molly Sauter and the strategies she outlines for obfuscation. Also, in what may be an important twist to the idea of the remote self offered by the present author (ibid) and which might be helpful in considering control systems in techno feudalism Molly Sauter speaks of 'mechanisms to distance the individual from the power of their vote'. Ideas like this are further 
pursued in Seven in the discussion of the self in the context of Big Tech.

At least Sauter and the figures she cites above are talking about the individual in the context of Big Tech. Other academic work or commentary on the $\mathrm{BBC}$ or CNN are US centred or Eurocentric and the political anthropology found there seems to admit no structures beyond the nation state in their terms of reference. Even the nation-state of China with its specific aspects of Big Tech is regarded in these mainstream television places as somehow 'beyond the pale'. Almost as though it is not quite a nation state.

In the last paper in this series I had concentrated on space and the efforts of Bezos, Musk and others. We are now talking about shells. An outer shell has been designated for Amazon satellites and within that another shell for Spacex satellites. These are sections, rings, if you like, around the earth. We might talk about the contour or shape of the algorithmic state and then the profile of operators in that context. For example the contours might be shell, hub, cyberspace and screen with several points between these. The profiles might be that Amazon operates in space with a shell, works extensively with hubs and cyberspace and uses screens. It has a profile across these basic contours.

Facebook does not operate in space but has a major presence on screen and in cyberspace. With these 
two contour shapes in mind we might turn to Eion Musk and Tesla and talk about another contour shape with strength in its shell in space but not a great presence in cyberspace. As this article and the ones that follow treat these shapes it is suggested that these are shapes of state, of algorithmic state and such concepts as tech feudalism might inform the general model suggested.

Turning to Musk and Bezos in space:

The satellite feud between Elon Musk's SpaceX and Jeff Bezos' Amazon spilled out into the open on social media this week, after brewing for months in meetings with regulators. It's only the latest spat in a new race among billionaires for a slice of a $\$ 1$ trillion telecommunications market.

Musk and Bezos, the two richest people in the world, are racing to build vast networks of satellites in low-Earth orbit capable of bringing high-speed broadband internet to rural parts of the world that have little or no access to the internet.

Last year, SpaceX began an invite-only beta program that now has thousands of users across the US, Canada, and the United Kingdom. Its initial price is pegged at $\$ 99$ a month, plus $\$ 499$ for a setup kit that includes a pizza-sized dish.

We might take these shells as one of a set of distinct physical points. Another might be space or sky very close to earth where drones deliver items. One idea which seems logical is that drones might deliver to 
the top of lamp posts. from here goods might be dropped to scouts that in turn deliver to houses. The drones recharge their batteries at the top of the poles as or after they drop the item.

These points are connected via the internet and to consider the process of connection we might start with the screen in the house. From there all points so far mentioned are connected.

Each point is a learning point. The screen organises information and improves it. Machine learning occurs at each point. There are plans at each point, the plan of Geoff Bezos to settle people in space for example which might proceed from the Amazon shell. The series of physical points and the information processes involved constitute a new form of state, a new structure or infrastructure, if you like.

There are matters of externality and mind. With the learning involved outside of human minds the Algorithmic State literally thinks on its own. One algorithm serves another and learns in tandem and sequence with others.

Some points are outside the scope of the nation state at least as this is commonly known and these are the shells of space and cyberspace. We could go back to Bezos and his vision of space settlement and ask whether people would be settled in areas owned by nation states on earth or in open zones, so to speak.

We could ask again, who owns the internet? 


\section{Conclusion}

Te return to the central or underlying argument, there are several spaces or forms of space involved; territorial space, outer space, cyberspace and living space, And there is data to be found and owned in each of these spaces. That data may be processed using algorithms in each space and across all spaces.

In this section I have suggested that what I had formerly described as the Algorithmic State might be considered in terms of techno feudalism. While a limited critique of the idea was mounted there seemed to be merit there.

Where I have been talking about the shape of the algorithmic state as distinct from the shape of the nation state in the next paper I intend to return to the history, of the algorithmic state. I have suggested a shape consisting, inter alia, of shells, hubs and screens. How are they integrated and combined if not through data and the use of algorithms? How are those things run if not through some kind of neo feudalism?

We might talk about the geography of state. A question might be made of the word geography in that that word is usually used of the physical space of the earth. This state has dimensions in outer space, near space and cyberspace as well as on the earth. There is a new shape of state in the shells of near space, the hubs in the sky or on land connected and found in cyberspace. In considering 
this shape of state we could look back in the Two Suns? series to the idea of the data of nations in Four and forward to the discussion of machine learning and the history of data usage in Six, the next section. 


\section{Bibliography}

Bleuca April 15 'Digital feudalism in a multipolar, unstable world' Responsible Statecraft, 2021

Brunton, Finn Nissenbaum, Helen Obfuscation A User's Guide for Privacy and Protest MIT Press 2015 Cleave, Peter Tribal and State-Like Political Formations in New Zealand Maori Society 17501900 The Journal of the Polynesian Society 1983

Collins, James C Good to Great:Why some companies Make the Leap... and others Don't, Harper 2001

Dumaine, Brian Bezonomics, How Amazon is changing our lives and what the World's best companies are learning from it, Simon and Schuster 2020

Ferenstein, Gregory February 26, "A Lot of Billionaires Are Giving to Democrats. Here's a DataDriven Look at Their Agenda," Forbes, 2016 "The Disruptors: Silicon Valley Elites' Vision of the Future," Winter 2017 City Journal

Galbraith, James "Inequality and the 2016 Election Outcome: A Dirty Secret and a Dilemma," New Geography, July 4, 2017

Giridharadas Winners Take All Video RSA Minimate 2019

Hastings, Reed and Meyer, Erin No Rules Rules: Netflix and the Culture of Reinvention Random House 2020

Huxley, Aldous Brave New World and Brave New World Revisited 2004 
Kotkin, Joel 'Neo-Feudalism in California' American Affairs Volume IV, Number 2 Summer 2020

O'Neill, Cathy Weapons of Math Destruction, Crown 2016

O'Neill, Cathy Ted Talk 2017

Piketty, Thomas Capital in the Twenty-First Century, trans. Arthur Goldhammer Cambridge: Harvard University Press 2014

Sauter, Molly May 24, 2017 Persuasion and the other thing: A critique of big data methodologies in politics in ETHNOGRAPHY MATTERS, Facebook 2017

Starr, Kevin Americans and the California Dream: 1850-1915 Oxford University Press 1994

\section{Internet sources}

Hirst K.Kris December 132018 'Feudalism - A Political System of Medieval Europe and Elsewhere' https://www.thoughtco.com/feudalism-politicalsystem-of-medieval-europe- 170918

Radio New Zealand 16.04.21, A deal to boost the local economy has been struck between the government and the global giant Amazon.

Venuto Damien Is Kris Faafoi being cowardly or clever on Google, Facebook?

21.03.20 New Zealand Herald Premium

Galloway, Scott Dec 222017 Its time: break up Big Tech

https://www.youtube.com/watch?v=1ebKI4x_k8A 
Leyden, Peter and Teixeira, Ruy California is the Future of American Politics https://medium.com/s/state-of-thefuture/california-is-the-future-6601cdf8caf8 Sackur, Stephen interview with Lina Khan on the BBC January 2021 